\title{
Bilateral serous cystadenofibroma of ovary with paratubal cyst: a rare case report
}

\section{Rajshree Dayanand Katke*, Shruti Gadekar, Asheq Shaikh, Bhagitra Aghav}

Department of Obstetrics \& Gynaecology, Cama and Albless Hospital, Mumbai, Maharashtra, India

Received: 31 May 2014

Accepted: 10 June 2014

\section{*Correspondence:}

Dr. Rajshree Dayanand Katke,

E-mail: drrajshrikatke@gmail.com

(C) 2014 Katke RD et al. This is an open-access article distributed under the terms of the Creative Commons Attribution Non-Commercial License, which permits unrestricted non-commercial use, distribution, and reproduction in any medium, provided the original work is properly cited.

\section{ABSTRACT}

Ovarian cystadenofibromas comprise very rare group of ovarian neoplasms with mixture of epithelial and fibrous stromal components. Here we present a case of a postmenopausal female who had bilateral ovarian cystadenofibromas along with a paratubal cyst.

Keywords: Ovarian cystadenofibroma, Paratubal cyst

\section{INTRODUCTION}

Ovarian cystadenofibromas are very rare tumours of ovary having both stromal as well as epithelial components. They account for about $1.7 \%$ of all ovarian neoplasms. ${ }^{1}$ Depending upon the epithelial cell type they are classified as serous, mucinous, endometriod, clear cell and mixed. ${ }^{2}$ Because of their complex solid cystic appearance on imaging they tend to mimic a malignant neoplasm pre-operatively.

\section{CASE REPORT}

A 42 year old multiparous (para 3 with 3 living issues) postmenopausal patient visited our out-patient department with complaint of pain in abdomen since 6 months. Patient was stable clinically. On examination her pulse was $82 / \mathrm{min}$ and blood pressure was $110 / 80 \mathrm{mmHg}$. Her respiratory and cardiovascular systems were normal. On abdominal examination a mass approximately of 2628 weeks size arising from pelvis was seen. It was a smooth surfaced mass with firm to hard consistency and restricted mobility. On per speculum examination her cervix and vagina were healthy. On per vaginal examination huge mass of $16 \mathrm{~cm}$ was felt arising from pelvis with restricted mobility. Another small mass of approximately $5 \mathrm{~cm} \times 5 \mathrm{~cm}$ was felt towards left side of this mass. Uterus was not felt separately. There was fullness in both fornices due to the mass and the mass was non tender. Patient was admitted and her routine investigations were sent; which were within normal limits. Tumor markers CA - 125 as on was $3.78 \mathrm{u} / \mathrm{ml}$, alpha foetoprotien - $0.515 \mathrm{IU} / \mathrm{ml}$ and CEA (carcinoembryonic antigen) was $0.69 \mathrm{IU} / \mathrm{ml}$.

Her CT scan was suggestive of well-defined solid cystic mass lesion of $14 \mathrm{~cm} \mathrm{x} 11.6 \mathrm{~cm} \mathrm{x} 11.4 \mathrm{~cm}$ with enhancing septa and solid components arising from right adnexa with right ovary not seen seperately. Another 5.4 $\mathrm{cm}$ x $5 \mathrm{~cm}$ x $6 \mathrm{~cm}$ similar morphology solid cystic lesion was seen in left adnexa with left ovary not seen separately. The impression given was that of bilateral ovarian carcinoma. Along with that an $8.3 \mathrm{~cm} \mathrm{x} 7.1 \mathrm{~cm} \mathrm{x}$ $8 \mathrm{~cm}$ non enhancing thin walled cystic lesion was present in left lower abdomen interspersed between bowel loops representing a benign mesenteric cyst.

Her pre-anaesthetic fitness was done and patient was posted for exploratory laparotomy with bilateral ovarian mass excision with total abdominal hysterectomy under general anaesthesia on 10/5/14 
Abdomen was opened by taking midline vertical incision. In situ a large ovarian mass of size $20 \times 15 \times 10 \mathrm{~cm}$ arising from right ovary was seen. The mass was hard in consistency with nodular surface and papillary excrescences. Another small mass of $5 \times 5 \times 5 \mathrm{~cm}$ was seen arising from left ovary; which had similar features. A third cystic mass of $8 \times 8 \times 5 \mathrm{~cm}$ was arising adjacent to left fallopian tube-suggestive of a paratubal cyst. This was a smooth surfaced purely cystic mass. The entire specimen was sent for frozen section. Frozen section report was suggestive of bilateral serous cystadenoma of ovary paratubal retention cyst. After getting this report abdomen was closed in layers after achieving haemostasis. Patient withstood the surgical procedure well.

Her post-operative period was uneventful. Complete suture removal was done on day 10 and the wound was healthy.

Final histopathology report came out to be bilateral serous cystadenofibroma with paratubal retention cyst. Patient did not require any treatment post-operatively.

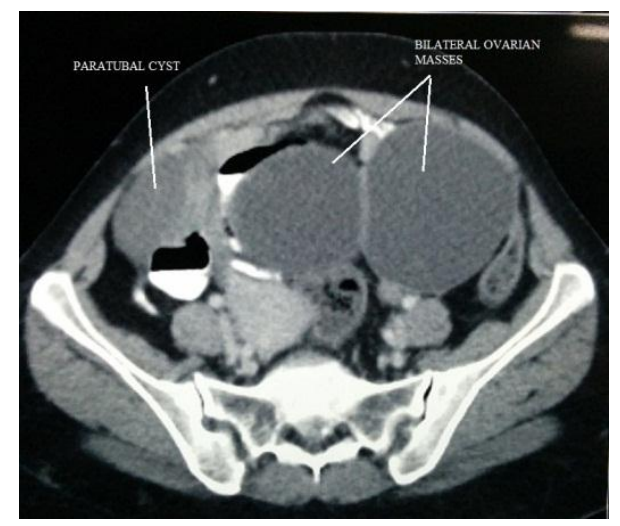

Figure 1: CT scan: paratubal cyst, bilateral ovarian masses.

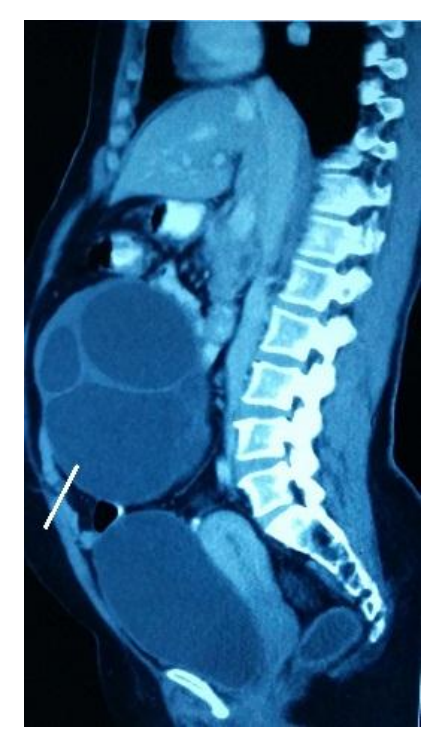

Figure 2: CT scan: benign mesenteric cyst.

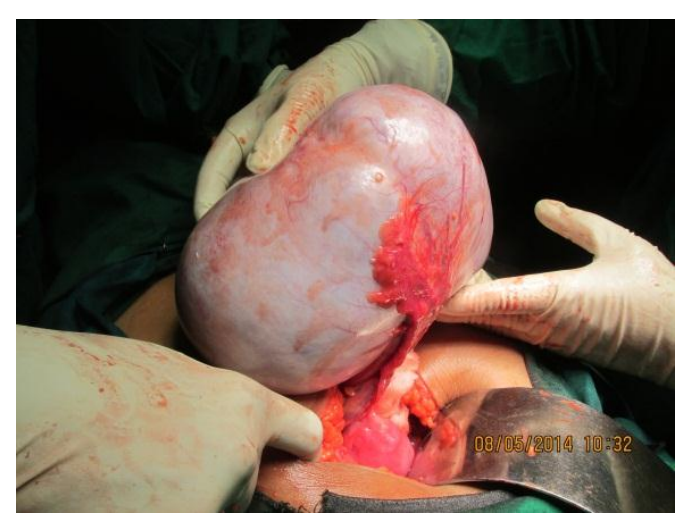

Figure 3: Abdomen was opened by taking midline vertical incision.

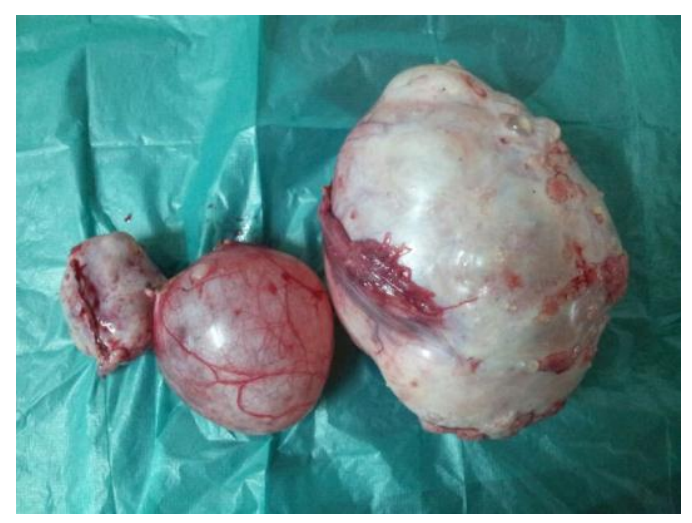

Figure 4: In situ a large ovarian mass of size 20x15x10 $\mathrm{cm}$ arising from right ovary was seen.

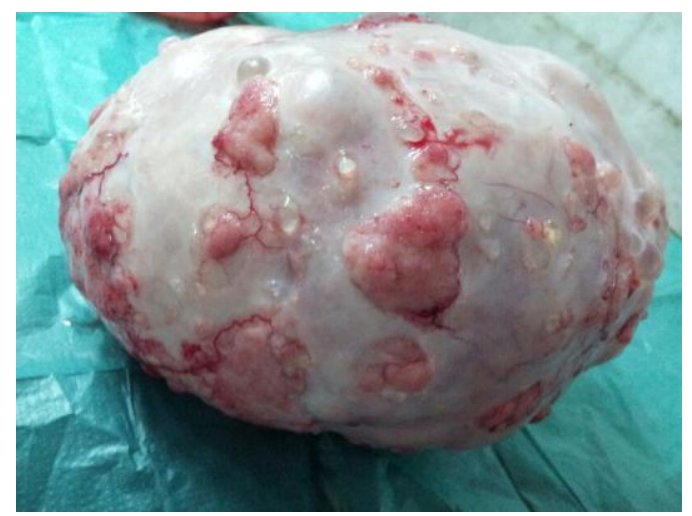

Figure 5: The ovarian mass was hard in consistency with nodular surface and papillary excrescences.

\section{DISCUSSION}

Ovarian cystadenofibromas arise from epithelial lining of the ovary and contain varying amount of stromal elements. Though ovarian cystadenomas are common tumours; cystadenofibromas are very rare accounting for only $1.7 \%$ of ovarian neoplasms. ${ }^{1,2}$ Bilateral tumours are even more rare. They can be bilateral in $15 \%$ of the cases. When the stroma occupies greater area than the cystic portion, the suffix "-fibroma" is added, as in "serous adenofibroma". Whereas when there is presence of more 
than 1 cyst over $1 \mathrm{~cm}$ in diameter the prefix "cyst" as in "cystadenofibroma" is added. The degree of epithelial proliferation and its relation to the stromal component of the tumour are the criteria used for the classification as benign, borderline, or malignant, although most of the reported ovarian cystadenofibromas are benign., ${ }^{3,4}$ These tumours are generally seen in the age group of 15 to 65 years. $^{3}$

Ovarian neoplasm usually presents with a pelvic mass with or without presence of ascites depending upon the stage of the disease. Malignancy is strongly suspected if the mass has complex solid cystic appearance with raised levels of tumor markers. On ultrasonography and computerised tomography an ovarian cystadenofibroma tends to appear as a complex solid and cystic mass thus mimicking a malignant neoplasm. On ultrasonography it may show a multiloculated solid cystic appearance with increased vascularity. ${ }^{5}$

MRI is the diagnostic modality which helps in preoperative diagnosis of this benign lesion as ovarian cystadenofibromas show characteristic "black sponge"like appearance on T2 weighted images. ${ }^{6}$ On T2weighted images, the solid components of the tumors show very low intensity, in which very high intense tiny cysts are present reflecting dense fibrous stromal proliferation with scattered small cystic glandular structures. Other tumors which have similar appearance are fibroma. fibrothecoma and Brenner tumour. The likelihood of malignancy increases with an increasing solid tissue portion and thicker septa and contrast enhancement usually facilitates differentiation between benign and malignant lesions. ${ }^{7}$

Even on gross examination this tumour tends to have appearance like that of a malignant one. So intraoperative frozen section becomes very important in preventing the patient from undergoing extensive surgery.

Given the rarity of tumour; exact incidence of bilaterality cannot be determined. One prior such case has been reported by Nisha and colleagues in 2012 where they had a 24 year old female with bilateral papillary serous cystadenofibroma.

Our case was very rare as our patient not only had cysadenofibroma; but also it was bilateral and along with it she also had a paratubal cyst.

Funding: No funding sources Conflict of interest: None declared

Ethical approval: Not required

\section{REFERENCES}

1. Cho SM, Byun JY, Rha SE et al. CT and MRI findings of cystadenofibromas of the ovary. Eur Radiol. 2004;14(5):798-804.

2. Byun JY. MR imaging findings of ovarian cystadenofibroma: clues for making the differential diagnosis from ovarian malignancy. Korean J Radiol. 2006;7(3):153-5.

3. B. Czernobilsky, R. Borenstein, M. Lancet. Cystadenofibroma of the ovary. A clinicopathologic study of 34 cases and comparison with serous cystadenoma. Cancer. 1974;34(6):1971-81.

4. H. L. Compton, F. M. Finck. Serous adenofibroma and cystadenofibroma of the ovary. Obstet Gynaecol. 1970;36(4):636-45.

5. Alcazar JL, Errasti T, Minguez JA, Galan MJ, Garcia-Manero M, Ceamanos C. Sonographic features for ovarian cystadenofibromas: spectrum of findings. J Ultrasound Med. 2001;20:915-9.

6. M. Takeuchi, K. Matsuzaki, M. Kusaka et al. Ovarian cystadenofibromas: characteristic magnetic resonance findings with pathologic correlation. J Comp Assist Tomogr. 2003;27(6):871-3.

7. Y. B. Jae. MR imaging findings of ovarian cystadenofibroma: clues for making the differential diagnosis from ovarian malignancy. Korean J Radiol. 2006;7(3):153-5.

DOI: $10.5455 / 2320-1770$. ijrcog20140913

Cite this article as: Katke RD, Gadekar S, Shaikh A, Aghav B. Bilateral serous cystadenofibroma of ovary with paratubal cyst: a rare case report. Int J Reprod Contracept Obstet Gynecol 2014;3:764-6. 